This item was submitted to Loughborough's Research Repository by the author.

Items in Figshare are protected by copyright, with all rights reserved, unless otherwise indicated.

\title{
A comparison of trackbed design methodologies: a case study from a heavy
} haul freight railway

PLEASE CITE THE PUBLISHED VERSION

PUBLISHER

(C) CRC Press (Taylor \& Francis Group)

VERSION

AM (Accepted Manuscript)

LICENCE

CC BY-NC-ND 4.0

\section{REPOSITORY RECORD}

Nelder, L.M., C. England, R.J. Armitage, M.J. Brough, Paul R. Fleming, and Matthew W. Frost. 2019. "A Comparison of Trackbed Design Methodologies: A Case Study from a Heavy Haul Freight Railway". figshare. https://hdl.handle.net/2134/5088. 
This item was submitted to Loughborough's Institutional Repository (https://dspace.lboro.ac.uk/) by the author and is made available under the following Creative Commons Licence conditions.

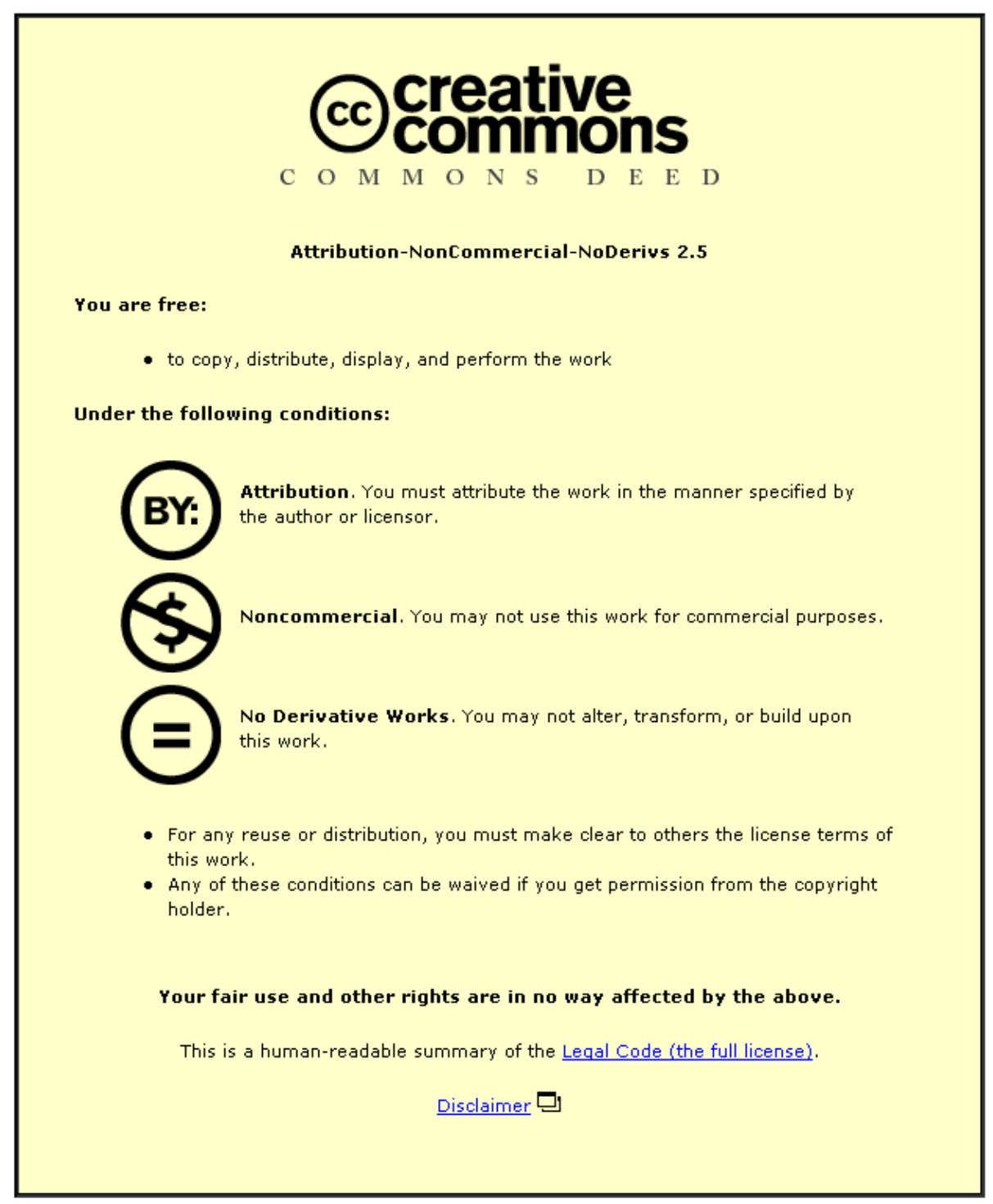

For the full text of this licence, please go to: http://creativecommons.org/licenses/by-nc-nd/2.5/ 


\title{
A Comparison of Trackbed Design Methodologies - A Case Study from a Heavy Haul Freight Railway
}

\author{
L.M.Nelder, C. England, R.J.Armitage and M.J.Brough \\ Scott Wilson Ltd, Nottingham, UK
}

P.R.Fleming and M.W.Frost

Loughborough University, UK

\begin{abstract}
One of the major roles of railway trackbed layers is to reduce vehicle induced stresses applied to the underlying subgrade to a level that limits the progressive build up of permanent deformation. The ability of trackbed layers to satisfy this requirement is dependent upon the materials used for construction and their thickness. Numerous design methods, (both empirical and analytical), have been developed across the World to evaluate trackbed design thickness. However, where there is limited information or experience of previous trackbed design with the specific materials or site conditions under consideration, the choice of methodology becomes one of engineering judgment, in assessing the significance and reliability of the design input parameters.
\end{abstract}

This paper describes a number of design methods which were assessed in a recent project to design a new heavy haul freight railway trackbed, founded on moisture sensitive subgrades, using locally available materials for the track support layers. The produced design thicknesses for each of the methods are compared for differing subgrade conditions. The results show considerable variation of thicknesses from each method with little consistent pattern to the variation. Reasons for these variations are suggested and the choice of the final design used for specific subgrade conditions are presented together with appropriate justification. Concluding on these issues, recommendations are made for a more considered approach to trackbed design.

\section{INTRODUCTION}

The design of trackbed support layer thickness has historically been based on empirical solutions formed from observation and experience. These solutions have been developed within the constraints of the geology and traffic loading experienced in their geographical catchments. While these solutions will remain valid when used within the range of their original development, once the traffic or subgrade conditions are altered the confidence with which they can be applied will inevitably be affected.

Most of the standards for trackbed design have also been developed to stand alongside corresponding standards on ballast type, rail/sleeper configurations, maintenance methods and vehicle suspension systems. The combination of these standards serves to optimize the network usage and to protect the track and rolling stock from excessive damage. Implicit within these standards are acceptable levels of deterioration within which operations can continue normally.

Provision of rail infrastructure in areas not covered by pre-existing design codes can present significant problems to the designer. It is often the case that the individual components have been sourced from differing regions and will not easily be incorporated into another design code.

This was the case in a project to improve the rail access to a new mining development in the Caribbean which is expected to carry freight traffic of 11 million tonnes per annum at a line speed of 25mph.This project involved designing trackbed layers for major upgrades to existing rail lines and the installation of new railway infrastructure. Extensive and detailed site and ground investigations where carried out as a preliminary phase of design (Brough et al. 2006) to determine the extent of subgrade variation. Additional laboratory tests were carried out to determine the mechanical behaviour of locally derived stone proposed as ballast for the construction as this differed considerably from the materials specified in the main design standards. The differences in subgrade and loading conditions envisioned in this design were significantly different from those encountered when using most standard design methods. For this reason it was decided to use a number of design methodologies to determine the depth of construction required to protect the subgrade and then to assess which method was most appropriate for each section of line. The methods used in the analysis are the most commonly applied national standards and a linear elastic model used by 
Scott Wilson for designing highway pavements, suitably modified to allow for rail wheel loading.

\section{DESIGN METHODS}

No suitable standard design code exists for the calculation of construction thickness for the axle loads proposed for this project in the Caribbean. The methods used in this project are the British Rail design chart standards (Heath and Shenton, 1972), UIC 719-R (UIC, 1994) the AREA Engineering Manual approach (Selig and Waters 1994) and a linear elastic model developed by Scott Wilson for use in pavement design.

The relevant parameters for design assume a static axle load of $31,000 \mathrm{~kg}$, an estimated annual traffic load of 11 million gross metric tones per year a line speed of $25 \mathrm{mph}$, an axle spacing of $2.8 \mathrm{~m}$ and a driving wheel diameter of 33 inches. From these a dynamic load factor based on Clarkes equation (Clarke 1957) of 1.25 has been calculated, from which a maximum applied stress of $243 \mathrm{kN} / \mathrm{m}^{2}$ was derived for the direct force applied by an individual sleeper to the underlying ballast. This stress assumed that the load applied by an axle over a sleeper is distributed $50 \%$ over the sleeper directly underneath the axle load and $25 \%$ over the two adjacent sleepers, which is a commonly used approximation that will vary depending on rail and trackbed relative stiffness.

One of the main aims of trackbed design is to provide a sufficient thickness of foundation material to reduce the stress applied to the top of the subgrade by loading to a level where there is negligible permanent deformation under each wheel load application; referred to as the threshold stress or threshold shear strength. The threshold shear strength in this design is assumed to be $50 \%$ of the shear strength determined from in-situ hand vane measurements obtained from trial pits. There was an additional requirement to consider the changes in shear strength within highly plastic clays due to seasonal moisture changes, as the site investigations were undertaken during relatively dry conditions. Where the plasticity index was greater than $65 \%$ the threshold values where reduce by a further $25 \%$ to allow for potential softening of materials based on the judgement of the senior design engineer.

\subsection{British Rail Design Approach}

This approach suggests that in order to reduce the stress level applied to below the threshold stress, granular thickness can be calculated from the following design chart which was based on laboratory studies undertaken on London Clay samples (Heath and Shenton, 1972 )

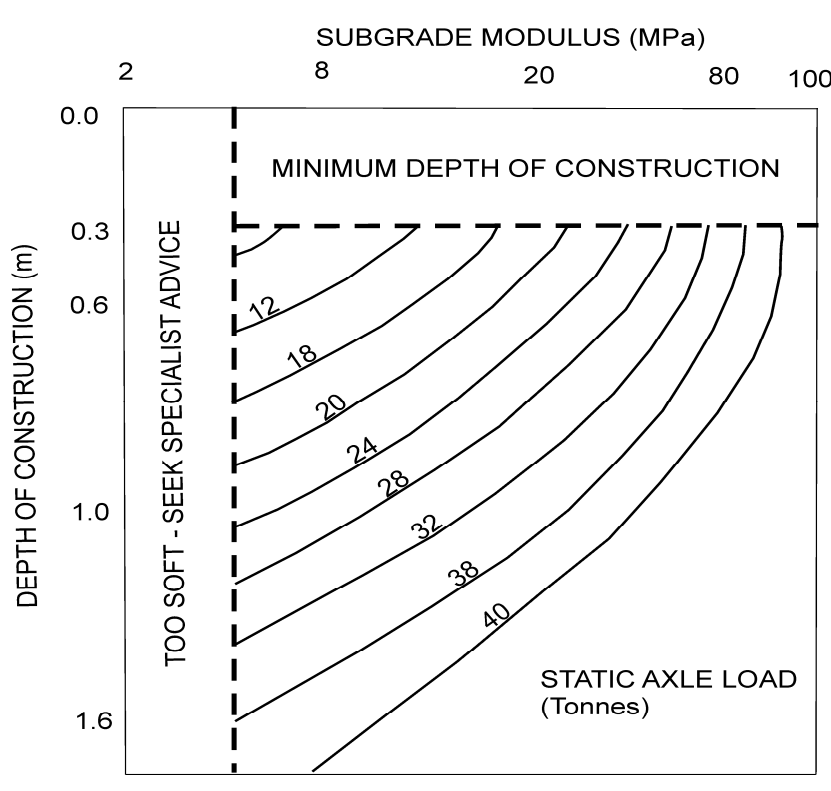

Figure 1. Britsh Rail trackbed thickness design chart (after Heath and Shenton, 1972)

For the purposes of this project the following assumptions were also made:

1 The depth of construction was based on a static axle load of 32 tonnes.

2 Subgrade resilient modulus, defined as the peak applied axial repeated stress divided by the samples recoverable axial strain was determined from either testing of recovered samples or estimated from the results of Dynamic Cone Penetrometer (DCP) testing, where samples could not be recovered.

3 Where existing layers of material are maintained in the new construction as granular sub-ballast, an equivalent foundation modulus (EFM) has been obtained from the equation:

$$
\mathrm{EFM}=143 * \text { Surface Deflection }{ }^{-1.0439} \mathrm{MPa}
$$

where the surface deflection was obtained from a proprietary linear elastic layer program using material properties obtained from the relevant site investigations.

\subsection{UIC $719 R$}

The UIC 719R approach, developed by the European Committee for Standardisation for Europe wide use, is an empirical method for calculating granular layer thickness based on soil descriptions and qualitative classification of the soil into bands applicable to European soils. For the purposes of this project soils were assigned to classifications equivalent to those in the UIC code based on observed ground conditions and material properties obtained from insitu and laboratory testing.

It was assumed that existing granular ballast materials, where present and of suitable quality, could be considered to be equivalent to sub-ballast for the purpose of the design; hence, where these materials 
remain in-situ their thickness needed to be subtracted from the calculated granular layer thickness. This approach demonstrates an advantage over other methods in that any existing suitable granular subgrade materials could be easily incorporated into the design to reduce the required new granular layer thickness.

For the purpose of this design the required bearing capacity of the sub-grade has been classified as Platform 2: 'average sub-grade' based on the required structural performance.

The overall thickness " $\mathrm{e}$ " is the sum of a number of factors (a-d, f-g etc on Figure 2) which relate to the subgrade conditions, proposed traffic speed, load and nature of traffic and trackbed structural requirements. The value of "E" depends on the required bearing capacity of the subgrade. The thickness of the prepared subgrade layer $\mathrm{e}_{\mathrm{f}}$ will depend on the soil type and the required platform bearing capacity.

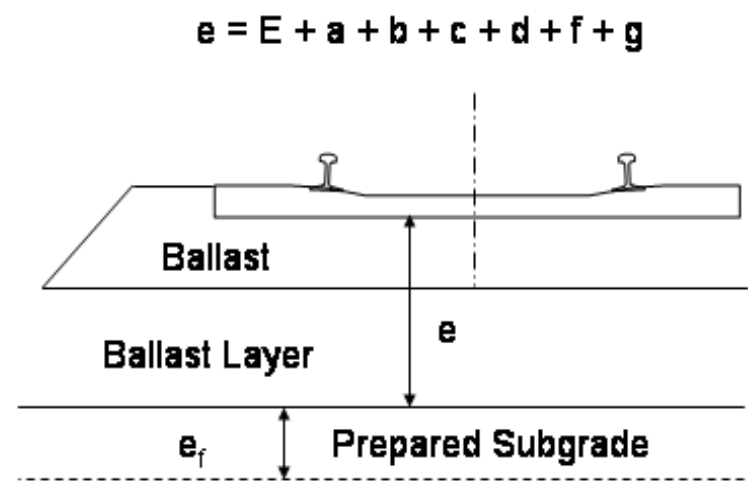

Figure 2. Calculation of Minimum Thickness of Trackbed (After UIC 1994)

For the purposes of this design, values of a, b, c, $\mathrm{f}$ and $g$ used in the calculation of granular thickness have been assumed to be zero in all calculations due to the low line speed and the lack of passenger comfort requirements. The value of $d$ is taken to be $0.12 \mathrm{~m}$ due to the high axle loads proposed in the design.

\subsection{AREA Engineering Manual Approach}

This approach uses equations developed by Love (Love 1928) and Talbot (Talbot 1919). The Talbot equation is largely empirical and was developed from full scale laboratory tests using relatively low wheel loads. The Love equation is a development of the Boussinesq equation for elastic analysis, where the point load regime is replaced with a uniform pressure. The equations are:

TALBOT EQUATION:

$$
P_{c}=\frac{16.8 P_{m}}{h^{1.25}}
$$

\section{LOVE EQUATION}

$$
P_{c}=P_{m}\left[1-\left(\frac{1}{1+r^{2} / h^{2}}\right)^{\frac{3}{2}}\right]
$$

Where $\mathrm{P}_{\mathrm{c}}=$ allowable subgrade pressure (psi); $\mathrm{P}_{\mathrm{m}}$ $=$ applied stress on ballast (psi); $h=$ ballast depth (inches); $r=$ radius of a circle whose area equals the sleeper bearing area (inches).

The Engineering Manual approach recommends a universal limit of 20 psi (140 kPa) for allowable subgrade pressure. However this approach was not used in this project as it was felt that it could lead to inadequate design over poor ground conditions and over design on more competent subgrades. Instead values of $\mathrm{P}_{\mathrm{c}}$ were calculated using Terzagi's equation (Terzarghi 1943) for undrained soils (undrained conditions), working on the assumption that the railway acts as a rectangular pad foundation of dimensions equal to the sleeper areas rather than a continuous footing. This approach designs against individual sleeper punching which is assumed to be the worst case failure mechanism. Allowable subgrade pressure is then assumed to be $50 \%$ of the ultimate bearing capacity, as calculated from the Skempton equation (Skempton 1951). Allowable subgrade pressures for granular subgrades have been conservatively estimated from the results of DCP testing. Safe bearing pressures can be related to the density of the packing (Waltham 1994) of the granular material, which in turn is related to the SPT N values (BS 5930:1999). DCP testing was used in this project for which there is no standard correlation to SPT values, so engineering judgement was used to approximate suitable values.

\subsection{Analytical Method using a Multi-Layer Elastic Model}

There is currently no standard analytical method to assess the thickness of railway ballast for a given subgrade condition and traffic loading. In order to develop an analytical model, knowledge of subgrade properties in terms of strength and stiffness, trackbed layer material properties, future traffic loading and relevant failure criteria are required. Two different failure criteria where considered to calculate ballast thickness:

- Limiting the shear stress applied to the subgrade under the locomotive axle load of $380 \mathrm{kN}$ to $50 \%$ of the subgrade material shear strength.

- Limiting the maximum ballast surface deflection under $125 \mathrm{kN}$ loading to $1.5 \mathrm{~mm}$, which is associated with typical UK mainline poor track per- 
formance (Armitage and Sharpe 2000). The $125 \mathrm{kN}$ represents $50 \%$ of a typical UK axle load assumed to be applied on one sleeper.

This second criteria recognises the importance of limiting ballast elastic deformation under loading, since large movements can allow particle reorientation and ultimately loss of track quality, even where the subgrade is not overstressed. Using the design principles adopted in the field of Pavement Engineering a model was developed to test the trackbed against these failure criteria. The trackbed structure comprising subgrade, existing contaminated granular material and new ballast were modelled as a multilayer linear elastic system where each layer is described by its stiffness, Poisson's ratio and thickness. An in-house multi-layer elastic program, used for pavement design, for nearly 20 years, was used to calculate the maximum shear stress at the top of the sub-grade and the deformation of the ballast surface under train loading for various assumed thicknesses of ballast. The calculated values were then compared with the subgrade material failure strength and the acceptable surface deflection of $1.5 \mathrm{~mm}$, respectively. If either of the failure criteria was breached then the granular thickness was increased until a satisfactory design was achieved.

Subgrade and existing granular layer stiffnesses, shear strengths and thicknesses were predicted from a combination of laboratory and in-situ testing and observations.

\section{DESIGN RESULTS}

The results in Tables 1-6 show a selection of combined granular/ballast layer thicknesses for trackbed on a range of subgrade types found along the proposed route. Where the thickness is given as "less than" the requirement was below $300 \mathrm{~mm}$, which has been assumed as the minimum for automated track maintenance by tamping.

\subsection{Rock Sub-grade}

The design values of granular thickness for a rock sub-grade are presented in Table 1.

\begin{tabular}{|l|c|c|c|}
\hline Method & Stiffness (MPa) & $\begin{array}{l}\text { Mode } \\
(\mathrm{mm})\end{array}$ & $\begin{array}{l}\text { High } \\
(\mathrm{mm})\end{array}$ \\
\hline Love eqn & 200 & $<300$ & $<300$ \\
\hline Talbot eqn & 200 & $<300$ & $<300$ \\
\hline BR & 200 & 300 & 300 \\
\hline UIC & 200 & 570 & 1200 \\
\hline LE Stress & 200 & - & - \\
\hline LE def & 200 & 300 & 300 \\
\hline
\end{tabular}

Table 1. Typical Design Values for Rock Sub-Grades

The high values using the UIC approach are as a result of a localized area of weak rock which has been highly weathered and was assigned a lower soil classification compared to other rock subgrades.
Within the range of values, the UIC design thickness comes out at around twice the value predicted by other methods. This is due to the automatic use of $550 \mathrm{~mm}$ of material specified for the P2 bearing classification.

The granular thickness specified in the design for rock subgrade was therefore set at $300 \mathrm{~mm}$. This is in agreement with most methods and provides sufficient depth for future automated track maintenance.

\subsection{Granular Sub-grade}

The granular material sub-grades are either densely or loosely compacted and the results for the two classes are separated and shown in Tables 2 and 3.

\begin{tabular}{|l|c|c|c|}
\hline Method & Stiffness (MPa) & $\begin{array}{l}\text { Mode } \\
(\mathrm{mm})\end{array}$ & $\begin{array}{l}\text { High } \\
(\mathrm{mm})\end{array}$ \\
\hline Love eqn & 50 & $<300$ & 600 \\
\hline Talbot eqn & 50 & $<300$ & 500 \\
\hline BR & 50 & 400 & 400 \\
\hline UIC & 50 & 670 & 670 \\
\hline LE Stress & 50 & - & - \\
\hline LE Def & 50 & 500 & 500 \\
\hline
\end{tabular}

Table 2. Typical Design Values for Loose Granular SubGrades

\begin{tabular}{|l|c|c|c|}
\hline Method & Stiffness (MPa) & $\begin{array}{l}\text { Mode } \\
(\mathrm{mm})\end{array}$ & $\begin{array}{l}\text { High } \\
(\mathrm{mm})\end{array}$ \\
\hline Love eqn & 80 & $<300$ & 600 \\
\hline Talbot eqn & 80 & $<300$ & 500 \\
\hline BR & 80 & 300 & 300 \\
\hline UIC & 80 & 670 & 670 \\
\hline LE Stress & 80 & - & - \\
\hline LE Def & 80 & 300 & 300 \\
\hline
\end{tabular}

Table 3. Typical Design Values for Dense Granular SubGrades

The granular material is typically layers of made ground to a depth of $1.2 \mathrm{~m}$, which comprises gravelly sands with varying but small quantities of clay. Once again the UIC method gives a higher construction thickness than the other methods, but does not distinguish between the different mechanical properties of the two subgrade density states. The BR and analytical methods show a slight increase in thickness for the less dense material reflecting the lower stiffness and higher susceptibility to deflection.

Within each density state there are is a range of acceptable threshold stresses related to the composition of the granular materials. This has an effect on the AREA Engineering Manual methods which are based on the mechanical bearing capacity of the materials, not the stiffness of the subgrade.

The granular layer thickness specified for these sections of trackbed are $300 \mathrm{~mm}$ for the $50 \mathrm{MPa}$ stiffness and $400 \mathrm{~mm}$ for the $80 \mathrm{MPa}$ stiffness in accordance with the BR design method. 


\subsection{Clay Sub-Grade}

The clay subgrades were divided into three categories (20,40, $60 \mathrm{MPa}$ stiffness) in order to assess a range of conditions. The stiffness was related to the undrained shear strength as measured by a hand vane in trial pits using the correlation given in BS5930 1999 section 41.3.2.

\begin{tabular}{|l|c|c|}
\hline Method & Stiffness (MPa) & Mode $(\mathrm{mm})$ \\
\hline Love eqn & 20 & 900 \\
\hline Talbot eqn & 20 & 800 \\
\hline BR & 20 & 900 \\
\hline UIC & 20 & - \\
\hline LE Stress & 20 & $>1000$ \\
\hline LE Def & 20 & $>1000$ \\
\hline
\end{tabular}

Table 3. Typical Design values for very soft to soft Clay Subgrades

\begin{tabular}{|l|c|c|c|c|}
\hline Method & $\begin{array}{l}\text { Stiffness } \\
(\mathrm{MPa})\end{array}$ & $\begin{array}{l}\text { Mode } \\
(\mathrm{mm})\end{array}$ & $\begin{array}{l}\text { High } \\
(\mathrm{mm})\end{array}$ & $\begin{array}{l}\text { Low } \\
(\mathrm{mm})\end{array}$ \\
\hline Love eqn & 40 & 500 & 800 & 500 \\
\hline Talbot eqn & 40 & 400 & 600 & 400 \\
\hline BR & 40 & 500 & 500 & 500 \\
\hline UIC & 40 & 1020 & 1020 & 1020 \\
\hline LE Stress & 40 & $>1000$ & $>1000$ & $>1000$ \\
\hline LE Def & 40 & 900 & 900 & 300 \\
\hline
\end{tabular}

Table 4. Typical Design values for firm Clay Sub-grades

\begin{tabular}{|l|c|c|c|c|}
\hline Method & $\begin{array}{l}\text { Stiffness } \\
(\mathrm{MPa})\end{array}$ & $\begin{array}{l}\text { Mode } \\
(\mathrm{mm})\end{array}$ & $\begin{array}{l}\text { High } \\
(\mathrm{mm})\end{array}$ & $\begin{array}{l}\text { Low } \\
(\mathrm{mm})\end{array}$ \\
\hline Love eqn & 60 & 400 & 500 & $<300$ \\
\hline Talbot eqn & 60 & 300 & 400 & $<300$ \\
\hline BR & 60 & 300 & 300 & 300 \\
\hline UIC & 60 & 1020 & 1020 & 1020 \\
\hline LE Stress & 60 & 1000 & $>1000$ & 400 \\
\hline LE Def & 60 & 300 & 300 & 300 \\
\hline
\end{tabular}

Table 5. Typical Design Values for stiff to very stiff Clay Subgrades

At lowest sub-grade stiffness there is a reasonably consistent agreement between all methods that a granular thickness of around $1 \mathrm{~m}$ is required. The UIC method could not be used for this quality subgrade since it was considered too poor and should be improved. As the subgrade stiffness increases to 40MPa the AREA and BR approaches show a decrease in required thickness, but the UIC and analytical methods both stipulate a thickness of around $1 \mathrm{~m}$. Within each subgrade type there was a wide range of allowable bearing pressures and threshold shear strengths which contributed to variation in design thickness Each design method also uses different parameters as a basis for their results; in particular the approach used to allow for the presence of existing granular material (such as old trackbed). Since clay subgrades vary considerably, due to differences in their stiffness and strength as a result of moisture changes, design methodologies that reflect these differences are preferable to those that don't.

In general the soft clay subgrades all required in excess of $1 \mathrm{~m}$ depth of granular material, as calcu- lated by the Linear Elastic Stress and Deflection design methods. Firm clay subgrades (either with or without existing sub-ballast) were felt to require a more conservative approach than that suggested by the AREA or BR manuals so the UIC method was stipulated, to allow for potential future softening. For stiff subgrades with no existing sub-ballast the UIC method was also stipulated, but where there was a thickness of sub-ballast up to $200 \mathrm{~mm}$ the BR method was used since there was a degree of subgrade protection already in place. These decisions were influenced by the results from the Linear Elastic analysis. Indeed, where there was a good thickness of sub-ballast, in excess of $200 \mathrm{~mm}$, over a stiff clay subgrade the Linear Elastic analysis was used to check for allowable deflections when using the $300 \mathrm{~mm}$ minimum depth of granular material specified to allow for tamping.

\subsection{General Design Considerations}

As can be seen from Tables $1-6$ and Figure 3 the results from the differing design methodologies can vary significantly. It can also be seen that although there is some general trend in the differences (thicker granular trackbed for weaker subgrades) there is no simple relationship that allows for direct comparison. This is not unexpected as the methods use differing material parameters and assumptions to determine the thickness of granular material.

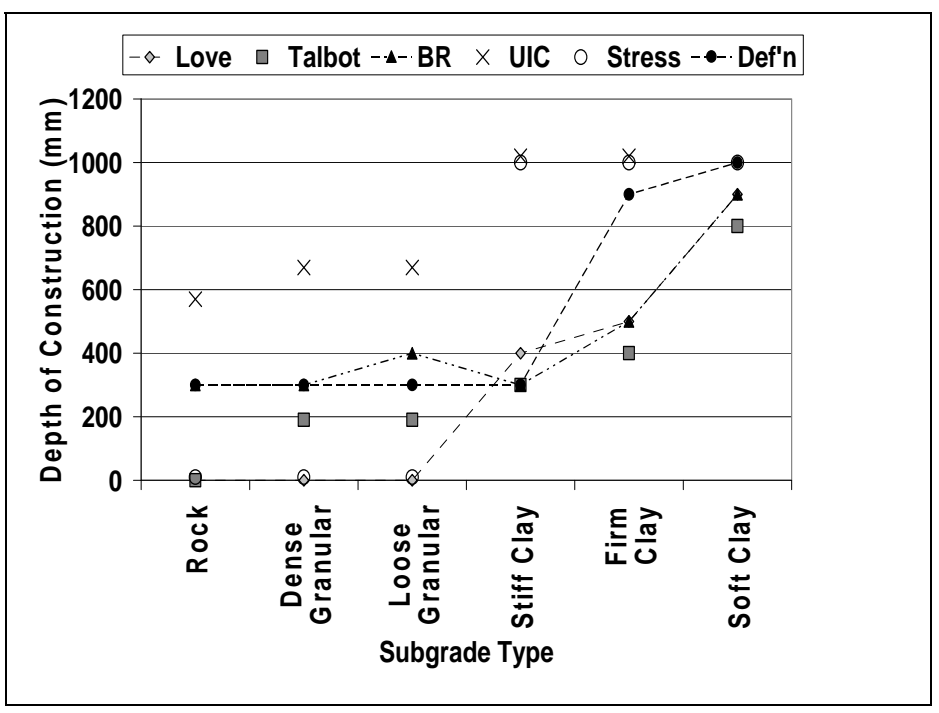

Figure 3 Summary Plot of Design Thicknesses

This lack of correlation highlights the problems faced by designers when specifying trackbed construction. The use of a design code in a situation outside of the limits upon which it was based may not produce adequate results when used elsewhere, especially when the method uses pre-prepared charts. If all methods are fundamentally based on providing adequate subgrade protection, then a more targeted design can be produced with increasing knowledge of the subgrade materials and properties. Otherwise, 
some methods may be unnecessarily conservative, or (perhaps worse) unable to deliver the level of performance required during the design life.

There is always a balance to be made between initial cost and future maintenance cost. This balance is one that can only be made by understanding the client's perspective, so it is essential to involve the client by explaining the options and agreeing the preferred whole life value approach. The ability to maintain a track (especially when single line, such as the one considered in this paper) involves knowledge of available plant, local expertise, freight operations, economic cost of downtime, etc.

In recent years a number of finite element methods have been proposed Chang et al (1980), Rose et al (2003) some of which are used in conjunction with elastic models. As yet, due to the complexity of modelling and limits of time, these methods are not suited for routine use, especially for the design of trackbed renewals, although they may find application in the design of new high speed lines where further optimisation of trackbed design is financially beneficial.

A more practical solution to this problem is to use a method based on Linear Elastic analysis, validated using in service trackbed data. This would allow designers to develop more appropriate solutions, using site specific materials data which is now available, underpinned by a method proven for pavement design over nearly three decades.

\section{CONCLUSIONS}

- Results from different design methodologies produced varying results for the required depth of trackbed construction on a range of subgrade types.

- In this project a number of design approaches were used and compared, which enabled the designer to specify a suitable trackbed construction.

- A design method based on a Linear Elastic analysis appears to provide realistic trackbed thicknesses in most cases. This makes use of material information that can be captured relatively easily during a site investigation, so is not constrained by regionally developed empiricism.

\section{FURTHER WORK}

The authors are currently developing the linear elastic model approach for trackbed design under an Engineering Doctorate scheme. It is hoped to optimise future designs by using a greater range of material specific parameters and a more realistic approximation of trackbed loading. Notwithstanding the inelastic nature of granular layers it is felt that, for practical purposes, this approach would be suitable for bridging the gap between the current extremes of design method (complex finite element versus simple empirical) to provide more cost efficient solutions.

\section{REFERENCES}

Armitage, R.A., P.Sharpe (2000). Implementing Optimal Trackbed Evaluation to Predict and Reduce Track Degradation. Infrastructure Maintenance and Research, London January 18-20

B.S. 5930 (1999). Code of Practice for Site Investigations. British Standards Institute.

Brough, M. J., C. England, et al. (2006). Trackbed Design for Heavy Haul Freight Routes: Case Study:Carribean Bauxite Mine. RailFound, Birmingham, University of Birmingham Press.

Chang, C.S., C.W. Adegoke and E.T. Selig (1980). The GEOTRACK Model for Railroad Track Performance. Journal of the Geotechnical Engineering Division, ASCE, 106(11) pp 1201-1218.

Clarke, C. W. (1957). Track Loading Fundamentals. The Railway Gazette. 106. pp26

Heath, D. L., M. J. Shenton, et al. (1972). "Design of Conventional Rail Track Foundations." Proc.Inst.Civ.Eng., 51, 251-267

Love, A. E. H. (1928). The Stress Produced in a Semi-infinite Body by Pressure on Part of the Boundary. Philosophical Transactions of the Royal Society. London. 228: 377-420.

Rose, J. G., S. Bei and W.B. Long. (2003). Kentrack: A Railway Trackbed Structural Design and Analysis Program. Proceedings of the AREMA Annual Conference, Chicago.

Selig, E. T. and J. M. Waters (1994). Track Geotechnology and Substructure Management. Thomas Telford, London.

Skempton, A. W. (1951). The Bearing Capacity of Clays. Proc. Building Research Congress. Vol 1 pp 180-189. London

Talbot, A. N. (1919). Second Progress Report of the Special Committee on Stresses in Track. Proceedings of the American Railway Engineering Association.

Terzarghi, K. (1943). Theoretical Soil Mechanics. John Wiley and Sons. New York,

UIC (1994). Earthworks and Trackbed Layers for Railway Lines. UIC Code 719 R, International Union of Railways, Paris, France.

Waltham, A.C.W. (1994). Foundations of Engineering Geology. Blackie Academic and Professional, London. 